\title{
NARRATIVAS DE FORMAÇÃO: POTENCIALIDADES E POSSIBILIDADES PARA A PESQUISA EM EDUCAÇÃO
}

\section{TRAINING NARRATIVES: POTENTIALITIES AND POSSIBILITIES FOR RESEARCH IN EDUCATION}

\author{
PEREIRA, Elder Bruno Fernandes ${ }^{1}$ \\ EUGÊNIO, Benedito Gonçalves ${ }^{2}$
}

\begin{abstract}
RESUMO
As narrativas possibilitam a articulação do individual com o social e têm sido empregadas em diversos estudos no campo educacional. Neste artigo, trazemos algumas contribuições da narrativa para a pesquisa em educação, destacando suas potencialidades e possibilidades para o estudo de diferentes questões do campo educacional. Trata-se de texto teórico em que apontamos as contribuições de autores que têm se dedicado ao estudo e utilização das narrativas. Inicialmente apresentamos as potencialidades da narrativa para a pesquisa. $\mathrm{Na}$ sequência, apontamos as contribuições da pesquisa autobiográfica empregando as narrativas. Destacamos as críticas feitas ao emprego das narrativas autobiográficas, assim como uma possível classificação que nos pode auxiliar ao propor pesquisas utilizando narrativas.
\end{abstract}

PalaVRAS-ChaVe: Narrativas; Pesquisa; Formação docente.

\section{ABSTRACT}

The narratives allow the articulation of the individual with the social and have been employed in several studies in the educational field. In this article, we bring some contributions of the narrative to the research in education, highlighting its potentialities and possibilities for the study of different issues of the educational field. It is a theoretical text in which we point out the contributions of authors who have been dedicated to the study and use of narratives. Initially we present the potential of the narrative for the research. In the sequence, we point out the contributions of the autobiographical research employing the narratives. We highlight the criticisms made to the use of the autobiographical narratives, as well as a possible classification that can help us in proposing research using narratives.

\footnotetext{
${ }^{1}$ Graduação em História (UNEB) e em Psicologia (Faculdade de Guanambi). Mestre em Ensino (UESB). Professor da Rede Estadual de Educação da Bahia. BA, Brasil. e-mail: eldergbi@hotmail.com

${ }^{2}$ Doutor em Educação (UNICAMP). Professor da Universidade Estadual do Sudoeste da Bahia (UESB) e do Programa de Pós-graduação em Ensino. Vitória da Conquista, BA, Brasil. ORCID: http://orcid.org/0000-0002-5781-764X . e-mail: dodoeugenio@gmail.com
} 
DOI: $10.12957 /$ e-mosaicos.2019.41983

KEYWORDS: Narratives; Search; Teacher training.

\section{INTRODUÇÃO}

Pensar o lugar que ocupa a estruturação das experiências formativas dentro da atuação profissional é um exercício que mobiliza o universo particular das memórias do sujeito. Suas inquietudes, desafios e sentidos construídos no transcorrer de suas vivências em diferentes momentos da vida vão se articulando de modo não unívoco e ainda assim particular incorporando e (re)construindo na prática a identidade profissional.

A pesquisa narrativa ou história de vida e narração lança um olhar epistemológico em como as implicações das singularidades vividas pelo sujeito dialogam com a formação de professores. A história de vida abordada por uma perspectiva biográfica permite uma investigação do processo formativo. As compreensões resultantes desse movimento refletem na construção de suas representações e apropriações.

Por intermédio da adequação de princípios epistemológicos e metodológicos, as narrativas de histórias de vida possibilitam alcançar uma meta-reflexão do conhecimento de si. Por esses elementos, considerando o contexto de sua produção, a abordagem biográfica é um instrumento valioso para os estudos ligados à formação continuada.

Desta forma, entendo que a abordagem biográfica e a autobiografia das trajetórias de escolarização e formação, tomadas como "narrativas de formação" inscrevem-se nesta abordagem epistemológica e metodológica, por compreendê-la como processo formativo e autoformativo, através das experiências dos atores em formação. Também porque esta abordagem constitui estratégia adequada e fértil para ampliar a compreensão do mundo escolar e de práticas culturais do cotidiano dos sujeitos em processo de formação (SOUZA, 2006, p. 26).

As narrativas possibilitam a articulação do individual com o social. Autores como Weller; Otte (2014), Muylaert et al (2014), Jovchelovitch; Bauer (2013), Moura; Nacarato (2017), Schutze (2011), Weller (2009), Weller; Zardo (2013), Souza (2008), Connelly; Clandini (2011), Bolívar; Domingo; Fernández (2001), Bertaux (2010) destacam a crescente utilização das narrativas nas pesquisas qualitativas, como pressuposto para entender a relação entre o indivíduo e a estrutura social, com ênfase nos resultados de experiências e trajetórias, trazendo as biografias singulares para o entendimento e compreensão dos complexos eventos/fenômenos sociais. 
Neste artigo, trazemos algumas contribuições da narrativa para a pesquisa em educação, destacando suas potencialidades e possibilidades para o estudo de diferentes questões do campo educacional.

\section{AS NARRATIVAS E SUAS POTENCIALIDADES PARA A PESQUISA EM EDUCAÇÃO}

A construção de narrativas tem como centralidade as definições que o sujeito atribui aos seus percursos. O sujeito revive a história que está nele ao retomar suas experiências no exercício de definição do que é real a seus olhos naquele momento. $\mathrm{O}$ ato de lembrar mobiliza bem mais do que os fatos vividos. É um processo de recriação que dialoga com o passado pelo filtro do tempo presente. $O$ resultante das conclusões sobre a visão de mundo, do outro e de si vão reconstruindo os sentidos e significados das memórias tidas como heranças dos trajetos vividos. As compreensões construídas por cada um no ato de lembrar representa a subjetividade frente aos aspectos históricos grafados por significações que se reconstroem no ato de pensar reflexivamente sobre tudo que se fez e faz.

A possibilidade de mobilizar as ações vividas no processo formativo de uma maneira mais ampla por pensar sobre determinadas questões a fim de compreendêlas a partir de novas reflexões pode, potencialmente, fomentar aperfeiçoamentos no pensar e agir pedagógico. O trabalho biográfico possibilita o resgate de situações cotidianas nos espaços pessoal e profissional por dialogar reflexivamente com as problemáticas dali resultantes.

Chamam-me a atenção às polaridades e discussões empreendidas sobre o lugar que ocupa o biográfico na esfera entre público e privado, nas relações postas entre vidas singulares, anonimato, respeito ao biografado e o trabalho de construção das biografias, como modo de revelar e desvelar situações cotidianas de sujeitos implicados em seus espaços pessoais e profissionais (SOUZA, 2014, p. 40).

Todos os campos e desdobramentos nas relações entre o sujeito e um dado objeto numa perspectiva colaborativa, resulta em singularidades em sua versão da história. As tidas lembranças reportam à identidade e às certezas mórficas sobre quem se é. Dado essa complexidade, a construção de critérios de análise desse material precisa ter uma articulação com os aspectos eleitos pelo sujeito para narrar sobre si.

Refletir sobre si mesmo por pensar sobre sua própria formação para então participar da formação do outro é um exercício salutar para que o professor se encontre em sua prática profissional. Os inúmeros desdobramentos nos cotidianos 
DOI: $10.12957 /$ e-mosaicos.2019.41983

advindos do emaranhamento de pluralidades perceptivas e singularidades relacionais atribuem às salas de aula características dinâmicas que não condizem com as possibilidades de aplicação de receitas padronizantes. Esse dinamismo cotidianamente irreplicável inerente às salas de aula exige dos profissionais da educação um constante repensar de sua prática que encontra na mediação biográfica uma possibilidade de estruturação de suas reflexões.

Em contextos de pesquisas e em práticas de formação, os acordos mútuos entre sujeitos em formação bem como profissionais em acompanhamento e processos de mediação biográfica dialogam sobre o lugar da oralidade e da escrita como dispositivos que possibilitam reflexões sobre a vida, a formação, as trajetórias individuais e coletivas, bem como sobre o respeito à liberdade, autonomia e democracia individual e social. Garantir o respeito às narrativas, aos percursos de vida-formação e possíveis superações de formas de controle sobre o biografo e o biografado ou entre a escrita (auto)biográfica e as disposições de formação são férteis para explicitar contextos, conjunturas sociais, marcas individuais dos homens e mulheres em suas manifestações sobre a vida (SOUZA, 2014, p. 40).

As pesquisas biográficas e autobiográficas tem sido importantes meios de produção e socialização de aprendizagens formativas. Perpassando por suas narrativas, é possível observar e construir novas análises tomando-as como referências teórico-metodológicas para a compreensão de diferentes fenômenos educacionais. Essa perspectiva tem ganhado espaço no cenário brasileiro como fonte de práticas formativas.

No campo educacional brasileiro, as pesquisas (auto)biográficas tem se consolidado como perspectiva de pesquisa e como práticas de formação, tendo em vista a oportunidade que remete tanto para pesquisadores, quanto para sujeitos em processo de formação narrarem suas experiências e explicitarem, através de suas narrativas orais e/ou escritas, diferentes marcas que possibilitam construções de identidades pessoais e coletivas (SOUZA, 2014, p. 40).

Esse importante espaço de partilha pela socialização de experiências individuais com todo o seu repertório de desafios e superações enriquece o repertório cognitivo tanto dos autores quanto dos seus leitores. A maturidade profissional toma maior volume quando a própria prática, ou a do outro, é repensada. No exercício da construção individual implicada com as questões socioculturais as marcas representativas de cada sujeito vão ganhando novas arestas 
DOI: $10.12957 / \mathrm{e}-\mathrm{mosaicos} .2019 .41983$

ao passo que o ser tem novas compreensões sobre si e sobre o outro. Essa percepção temporal da existencialidade vai se reconstruindo no decorrer da vida o que amplia as possibilidades de análise de estudos (auto)biográficos.

As diferentes formas de expressão típicas da individualidade humana geram diferentes formas de representação do cotidiano que por sua vez resultam em formas distintas de enfrentamento de situações problema. O revisitar de percursos e trajetórias com o intento de partilhar experiências e narrativas implica em acréscimo quanto à reflexividade na reconstrução da identidade profissional.

As disposições construídas num processo de entrevista abrem muitas possibilidades de sentido, formação, compreensão e marcas biográficas da vida entre entrevistador e entrevistado, frente à partilha de experiências de vida e de percursos biográficos vinculados a projetos de pesquisa ou a práticas de formação (SOUZA, 2014, p. 42).

As aprendizagens construídas ao longo da vida amparadas pelo exercício de conhecimento de si é que dão as singularidades de significados aos diferentes fenômenos que compõem a vida. No cenário de pesquisa a forma de apreensão e construção de dados rememorando reflexivamente momentos vividos implica diretamente na relação entre pesquisador com o objeto de pesquisa. Por esses parâmetros é razoável compreender que o papel dos atores da pesquisa proposta seja respaldado pelo modelo interativo ou dialógico.

(...) o modelo interativo ou dialógico adota uma nova relação de lugar entre o pesquisador e os atores sociais, tendo em vista uma coconstrução de sentido, porque não é redutível à consciência que tem dela o sujeito e também à análise construída pelo pesquisador. Compreendo que a dimensão interativa e dialógica, muito fortemente utilizada na abordagem biográfica, possibilita apreender as memórias e histórias de formação no sentido da investigação/formação tanto para o pesquisador, quanto para os sujeitos envolvidos e implicados com o projeto de formação (SOUZA, 2006, p. 27).

É razoável vislumbrar a interação entre pesquisador e pesquisado como forma legítima de alcançar compreensões relacionadas a significações diversas manifestas no cotidiano escolar. No âmbito de pesquisas sócio- educacionais as vozes dos atores sociais culturalmente situados possuem vital importância para o resgate da memória histórica em suas singularidades. Como há um intermédio da fala na construção de dados relativos à história de vida/formação pode-se definir a prerrogativa da história 
DOI: $10.12957 / \mathrm{e}-\mathrm{mosaicos} .2019 .41983$

oral como campo de definições. Nesses termos, os sujeitos da pesquisa possuem uma maior liberdade em expressar-se durante os diálogos.

(...) na história de vida, diferente do depoimento, quem decide o que deve ou não ser contado é o ator, a partir da narrativa da sua vida, não exercendo papel importante na cronologia dos acontecimentos e sim o percurso vivido pelo mesmo. Ainda que o pesquisador dirija a conversa, de forma sutil, é o informante que determina o 'dizível' da sua história, subjetividade e os percursos da sua vida (SOUZA, 2006, p. 29).

É provável que uma pesquisa que caminhe por um terreno pavimentado pelos preceitos da dialogia, história oral e narrativa ofereça possibilidades para a compreensão e ressignificações de memórias e histórias de professores em processo de formação continuada.

Para maximizar as potencialidades de uma pesquisa com instrumentos narrativos é preciso organizar elementos de diferentes espaços que dialoguem harmonicamente entre si. As complexidades envoltas nas experiências narradas exigem do pesquisador robusto empenho no manuseio desse material. Segundo Souza (2014, p. 43-46), o mapeamento e a análise das unidades temáticas perpassam por três tempos de análise que mantem aproximações entre si.

(...) o Tempo I centra-se na organização e leitura das narrativas, tendo em vista a construção do perfil do grupo pesquisado, para, em seguida avançar na leitura cruzada, a fim de apreender marcas singulares, regularidades e irregularidades do conjunto das histórias de vida-formação.

No que se refere ao Tempo II - Leitura temática ou unidades de análise temática/descritiva -, cabe destacar que o mesmo vincula-se às leituras cruzadas (Tempo I), tendo em vista a construção do perfil biográfico do grupo pesquisado e a possibilidade de apreensão de regularidades, irregularidades, particularidades e subjetividades de cada história individualmente e do conjunto das narrativas do grupo, mediante a organização temática e agrupamento de unidades de análise que possibilitam a compreensão-interpretação do texto narrativo, através do seu universo de significados e significantes. Cabe destacar que o objeto central da análise temática, como tempo II, consiste na construção, após a leitura cruzada, das unidades de análise temática, tendo em vista a análise compreensivainterpretativa.

O Tempo III - análise interpretativa-compreensiva - vincula-se ao processo de análise, desde o seu início, visto que exige leituras e 
releituras individuais e em seu conjunto do corpus das narrativas, recorrendo aos agrupamentos das unidades de análise temática e/ou ao conjunto das narrativas e das fontes utilizadas.

As narrativas no contexto da prática formativa centram sua trajetória nos aspectos históricos intercalados com cada individualidade subjetivamente construída. As análises e contribuições de uma pesquisa-formação para o desenvolvimento de práticas pedagógicas voltadas à desarticulação de possíveis ideologias racistas no cotidiano escolar têm seus elementos acrescidos ricamente pelo instrumento da narrativa.

Averiguar as (re)significações dos professores participantes do processo formativo no que se refere à sua postura pessoal e profissional frente à atuação pedagógica é proporcionar novos caminhos para aprendizagens significativas. Perceber o racismo como problema socializado no universo escolar é um passo importante a ser dado por docentes que pretendem colocar-se em um caminho avesso a essa prática de destruição do ser em vários aspectos da vida. Acredita-se que a narrativa da ação de uma formação continuada, mobilizadora de coesões e fragilidades do viver a experiência docente, possa contribuir com instrumentalização cognitiva de práticas destinadas a desconstrução de ações racistas no cotidiano escolar.

\section{As CONTRIBUIÇÕES DA PESQUISA AUTOBIOGRÁFICA POR MEIO DA NARRATIVA}

A narrativa tem ganhado destaque e credibilidade na pesquisa educacional. Sua legitimidade distinta se dá por não abstrair o fator humano de suas variáveis. Sendo uma alternativa ao objetivismo positivista, seu aporte teórico metodológico abraça as relações experimentadas pelos indivíduos como base para o entendimento das ações humanas. Esse não silenciar da subjetividade proporciona uma singular legitimidade quando se fala sobre a existencialidade humana.

Bolívar (2002) aponta a narrativa por destacar sua relevância na pesquisa educacional por introduzir nesse campo uma forma valiosa de construção de conhecimento. Além disso, 0 autor elege como objetivos passíveis de serem alcançados por meio da narrativa. Ele assinala que seu aporte metodológico dar conta da atual recomposição das categorias epistemológicas do que se entende por fazer ciência; mostra as principais linhas de fundamentação epistemológica das histórias autobiográfico, ecoando as disputas teóricas e epistemológicas que ocorreram nos últimos anos; reafirma como um modo próprio (narrativo) de conhecer; e que seus princípios teóricos da abordagem narrativa compõem uma própria maneira de investigação.

O método biográfico é fruto de críticas à objetividade que caracterizaram as metodologias positivistas. Suas caraterísticas metodológicas alicerçam um aporte 
DOI: $10.12957 / \mathrm{e}-\mathrm{mosaicos} .2019 .41983$

teórico que municiam o sujeito na compreensão de sua vida nos seus passos cotidiano.

Segundo Santos e Garms (2014), duas são as principais as críticas feitas ao método biográfico. A primeira trata da vinculação da subjetividade como um valor de conhecimento uma vez que a realidade é lida do ponto de vista de um indivíduo historicamente determinado. O segundo aspecto é que, por ser qualitativo, subjetivo e distante de esquemas de hipótese e verificação, o método biográfico projeta-se fora do quadro epistemológico até então estabelecido para as ciências sociais. Ao problematizar as críticas citadas, o autor reverter conceitualmente aquilo que era visto como ponto fraco em prerrogativas desejadas. É na ausência de objetividade quantitativa e por sustentar a versão qualitativa dos dados que dá o status de especificidade heurística do método referido.

Devido a sua estrutura peculiar, alguns cuidados devem ser observados para que essa estratégia de estudo não seja utilizada de modo inadequado. Sua concepção não é apropriada para fomentar generalizações. O pressuposto da subjetividade inerente ao método não dialoga com 0 intento de criação de padronizações de modelos interpretativos. O almejado em seus resultados são sua historicidade e univocidade.

Tendo a educação como fenômeno social e a interação dos sujeitos como sua mola propulsora, a posição central na construção dos dados passa pela autointerpretação. Não é somente uma questão de metodologia, mas uma forma de construir a realidade.

A individualidade subjetiva é uma condição necessária do conhecimento social. Ela é resgatada pela narrativa por dar voz a importantes dimensões na construção social das ações do sujeito. Parte-se do pressuposto de que toda construção de significados advém das interpretações do sujeito. A priorização da questão dialógica privilegia o olhar que busca o entendimento da dinâmica entre a intersubjetividade como construção social.

A narrativa opera como instrumento do pensamento ao construir a realidade. As esferas do pessoal e profissional estão imbricadas e ganham manifestação de maneira interligada. A narrativa de nós nos ajuda a perceber como o sujeito é construindo profissionalmente, através de um olhar mais personalizado. Quando se revisita um tempo passado de nossas vidas com um olhar implicado, pode-se trazer à tona novos significados do nosso presente.

A interação de múltiplas trajetórias colocadas como mobilizadoras de verdades internas reforça o exercício do autoconhecimento já que essa trafega pelas versões que se tem das experiências vividas. A partilha dessas experiências tem a potencialidade de proporcionar novas aprendizagens para o sujeito assim como para o outro.

Olhar para o passado pode ajudar-nos a encontrar explicação para significados nas ações que temos hoje como pessoas que foram 
construindo um percurso pessoal e profissional rico de cruzamentos com os outros e a dar sentido ao nosso posicionamento como professoras e formadoras de professores.

0 recurso à narrativa autobiográfica inscreve-se na ideia de que, ao narrarmos episódios com significado, os analisaremos de uma forma contextualizada, tentando que essa análise ponha em evidência emoções, experiências ou pequenos fatos marcantes, dos quais antes não nos tínhamos apercebido (FREITAS; GALVÃO, 2007, p.220).

Esse novo paradigma coloca o sujeito como protagonista no processo de compreensão da realidade. A legitimidade dos resultados obtidos monta-se entre a experiência vivida e suas representações. Tendo a educação como locus de pesquisa nesse movimento onde o eu é refúgio e reinventor do próprio eu, impera a necessidade da contextualização entre a prática educativa e o professor por levar em consideração as dimensões existenciais do ser.

Rompiendo decididamente con una concepción de racionalidad instrumental o tecnológica de la educación, em la cualla enseñanza es um medio para conseguir determinados resultados, la narratividad se dirige a la naturaleza contextual, específica y compleja de los procesos educativos, importando el juicio del profesoren este proceso, que siempre incluye, además de los aspectos técnicos, dimensiones morales, emotivas y políticas (BOLÍVAR, 2002, p. 7).

A especificidade do método autobiográfico origina-se dos materiais utilizados quer podem ser, segundo Santos e Garms (2011), primários e secundários. Os primários são as narrativas autobiográficas recolhidas por um pesquisador por meio de entrevistas. Os secundários são materiais de toda espécie, tais como correspondências, fotografias, documentos oficiais, processos verbais, recortes de jornal etc. embora os materiais secundários apresentem maior objetividade é no primário que as sutilezas são desveladas.

Para que as narrativas autobiográficas embebidas em subjetividade adquiram robusteza como objeto de conhecimento científico, alguns elementos precisam ser entendidos e incorporados na análise e construção de dados. Sendo o sujeito um ser ímpar, suas apropriações de sentido para com um fenômeno relatam sobre as relações dele com 0 mundo. Assim sendo, o processo de interiorização e exteriorização explicita o caráter dinâmico modelado pela subjetividade.

Caminhando pelos preceitos epistemológicos estabelecidos pelo método, as narrativas (auto) biográficas corrobora potencialmente como um instrumento de investigação para a análise da formação de professores. As subjetividades inerentes à práxis humana podem indicar reverberações decorrentes do interagir socialmente. 
Sobre o processo de formação do sujeito, o uso da metodologia de investigação de natureza biográfica mostra que a construção da biografia narrativa não é uma narrativa de vida, tal como resultaria da narração de uma história de vida considerada em sua globalidade. É o fruto de um processo de reflexão parcial, a meio caminho do percurso seguido pelo sujeito no decorrer da vida. Cada etapa desse percurso se constitui tanto no fim de uma interrogação como é o ponto de partida de outra. O trabalho com narrativas autobiográficas implica a forte participação do indivíduo que, por sua vez, se compromete com o processo de reflexão, orientado pelo seu interesse, e que o leva a definir e a compreender seu processo de formação (SANTOS; GARMS, 2011, p. 4099).

O foco é na discussão das itinerâncias profissional dos indivíduos para buscar compreensões de diferentes aspectos ligados às questões individuais. $\mathrm{O}$ sujeito fala a partir do lugar de protagonista em seu processo formativo e crítico investigador de si. Por esses termos, sua experiência com a prática pedagógica e suas percepções sobre o ensino ganham forma diante de seus olhos. $O$ resultante desse processo pode se valer de (re)construção de saberes no desenvolvimento pessoal e profissional.

Ordenando as experiências do individuo como forma de compreender o mundo, o modo narrativo foca em experiências e ações dependentes de contextos específicos. Sua riquesa de nuancias é incompatível a categorias abstratas ou generalizações. Trata-se de uma forma legítima de compreender como os homens dão sentido ao que fazem.

Así, frente a un modo de argumentar lógico, el modo narrativo de conocimiento parte de que las acciones humanas son únicas y no repetibles, dirigiéndose a sus características distintivas. Su riqueza de matices no puede, entonces, ser exhibida em definiciones, categorías o proposiciones abstractas. Si el pensamiento paradigmático se expressa en conceptos, el narrativo lo hace por descripciones anecdóticas de incidentes particulares, en forma de relatos que permiten compreender como los humanos dan sentido a lo que hacen. Por ello mismo, no debe, a riesgo de estrangularlo, ser reducido a un conjunto de categorias abstractas o generales que anulen su singularidad (BOLÍVAR, 2002, p. 10).

A narrativa carrega em seu bojo um potencial de organização do pensamento e da realidade na estruturação de aprendizagens. Por meio delas, são retomadas as vivências visceralmente entrelaçadas em dinâmicas reais ou imaginárias. Esse 
DOI: $10.12957 / \mathrm{e}-\mathrm{mosaicos} .2019 .41983$

processo compartilha resoluções de problemas alargando a compreensão da realidade, por possibilitar ao outro uma identificação com a história relatada. $O$ ator de compartilhar experiências pode mobilizar saberes para a resolução de outras problemáticas.

É justamente nesse processo de identificação que se pode encontrar o potencial educativo das narrativas, pois as histórias possuem imagens, mitos e metáforas de cunho moral que contribuem para nosso desenvolvimento como seres humanos. Em outras palavras, as narrativas cujas tramas promovem a reflexão sobre as complexidades da vida preparam-nos, individual ou coletivamente, para o enfrentamento de suas dificuldades e complicações (SANTOS; GARMS, 2011, p. 4101).

Ao narrar questões que grafaram momentos significativos na construção da identidade profissional, o professor tem a oportunidade de reconstruir os sentidos deixados pelas experiências vividas bem como sua ação pedagógica.

As narrativas mobilizam sentidos que podem levar o professor a redimensionar suas perspectivas sobre o ensino. Seguindo o proposto por Santos e Garms (2014) em situações de formação de professores, é interessante explorar variados tipos de narrativas, conforme demonstrado abaixo:

\section{QUADRO 1: TIPOS DE NARRATIVAS}

\begin{tabular}{|l|l|}
\hline \multicolumn{1}{|c|}{ Tipos de narrativas } & \multicolumn{1}{c|}{ Características } \\
\hline Narrativa de crítica social & $\begin{array}{l}\text { Tem como uma das funções estimular os sujeitos a serem } \\
\text { mais críticos em relação aos papéis da sociedade e da } \\
\text { educação e ajudá-los compreender o papel histórico da } \\
\text { escola diante das injustiças sociais }\end{array}$ \\
\hline Narrativas de aprendizagem & $\begin{array}{l}\text { Auxiliam professores na busca de conhecimentos a } \\
\text { respeito da profissão que Ihes permitam tornarem-se bons } \\
\text { professores }\end{array}$ \\
\hline Narrativas de práticas reflexivas & $\begin{array}{l}\text { Baseiam-se na capacidade dos professores de refletir, } \\
\text { questionar e transformar sua prática diária }\end{array}$ \\
\hline Narrativas sobre trajetórias & $\begin{array}{l}\text { Constituem em uma oportunidade para que os professores } \\
\text { reflitam sobre sua vida e sua carreira e incorpora todos os } \\
\text { tipos de narrativas. }\end{array}$ \\
\hline Narrativas de espera & $\begin{array}{l}\text { São capazes de estimular o otimismo e a imaginação por } \\
\text { apontar para possibilidades de uma educação mais sólida }\end{array}$ \\
\hline Narrativas de liberdade & $\begin{array}{l}\text { Baseiam-se na capacidade de promover mudanças nas } \\
\text { práticas convencionais de ensino para alcançar objetivos } \\
\text { que antes pareciam inalcançáveis }\end{array}$ \\
\hline
\end{tabular}

Fonte: Elaboração dos autores 
A utilização de um desses tipos de narrativas depende do objeto de pesquisa. Ainda está por ser realizado um mapeamento das pesquisas empregando narrativas e sua classificação tendo por base a categorização acima, o que com certeza contribuirá para termos elementos que possibilitem entender a quais tipos de narrativas os pesquisadores brasileiros tem recorrido ao elaborarem pesquisas empregando essa perspectiva metodológica.

Por intermédio de análises dessas narrativas, os professores têm a oportunidade de refletir e aprender sobre os processos de aprendizagem, os impactos de determinadas experiências educativas, os problemas e as dificuldades que enfrentam ao longo de sua carreira, as estratégias que utilizam para superá-las, a importância das práticas colaborativas, entre outros aspectos. O processo de aprendizagem torna-se mútuo (SANTOS; GARMS, 2011).

Envolvido em tantas complexidades, Bolívar (2002) aponta dois tipos de pesquisa narrativa em educação. Ambas são legítimas fontes construtoras de conhecimento, mas com distinções entre elas. A primeira delas é a "análise paradigmática de dados narrativos", que são estudos baseados em narrativas, história oral ou de vida, mas cuja análise (geralmente chamada de "qualitativa") prossegue por tipologias paradigmáticas, taxonomias ou categorias, para alcançar certas generalizações do grupo estudado. Os dados obtidos são examinados de acordo com padrões gerais e comuns.

Do ponto de vista temporário, os dados podem ser esclarecidos de maneira diacrônica ou síncrona. Na forma diacrónica, os dados contêm uma informação temporária sobre as relações sequenciais entre eventos, descrevem quando um evento ocorreu e os efeitos que teve sobre o seguinte. Então, na ordenação autobiográfica, referências são incluídas para quando e por que certas ações tiveram tais ou tais resultados ou impactos. Na ordem síncrona eles são enquadrados como respostas categóricas às questões do pesquisador.

A segunda forma sugerida pelo autor é a análise narrativa propriamente dita. Trata-se de estudos baseados em casos particulares (ações e eventos), mas cuja análise (narrativa, no sentido estrito) produz a narração de um enredo ou argumento, através de uma narrativa de dados significativos. Aqui não são procurados elementos comuns, mas elementos singulares que moldam a história.

A peculiaridade da análise narrativa propriamente dita da análise paradigmática de dados narrativos é que o primeiro produz resultados de uma narração particular sem aspiração a generalizações. A tarefa do pesquisador, neste tipo de análise, é configurar os elementos dos dados em uma história que unifica e dá significado aos dados, a fim de expressar de maneira autêntica a vida do indivíduo, sem manipular a voz dos participantes.

A análise requer que o pesquisador desenvolva argumentos que permitam vincular temporariamente ou tematicamente elementos, dando uma resposta 
DOI: $10.12957 / \mathrm{e}-\mathrm{mosaicos} .2019 .41983$

abrangente sobre o porquê de algo ter acontecido. Os dados podem vir de fontes muito diferentes, mas a questão é que elas são integradas, interpretadas em uma intriga narrativa. O objetivo final é, neste caso revelar o caráter único de um caso individual e fornecem uma compreensão de sua particular complexidade ou idiossincrasia (BOLÍVAR, 2002).

Se por um lado o relato narrativo apresenta o ponto forte de não expropriar as vozes dos sujeitos investigados, por outro, é preciso ter cautela para não sacralizar o discurso, superestimando-os. Referindo-se aos professores, é importante lembrar que suas histórias de vida é que dão certos significados aos fatos. Cabe ao pesquisador uma análise investigativa para compreender porque eles dizem o que dizem. Para que essas histórias sejam relevantes para os fins da investigação, devem também submeter-se acertos modos de paradigma aceitos para analisar a informação (BOLÍVAR, 2002).

A construção de um relato biográfico-narrativo passa pelo processo de síntese de dados com solidez suficiente para retratar a trama dentro de um contexto. 0 penetrar no universo simbólico que é a fonte geradora de significados do mundo que se vive, o pesquisador precisa ter a sensibilidade e maturidade metodológica capaz de entender o fato construído humanamente. Quando se evoca o passado, junto a ele vem o julgamento referenciado no hoje. Mudando o contexto de uma mesma pergunta, podem-se obter respostas diferentes.

Por colocar o sujeito no lugar central, a narrativa como metodologia de pesquisa explora as dimensões individuais do sujeito em sua complexidade existencial. As singularidades produtoras de sentido experiencial de cada sujeito revelam as estratégias decorrentes do enfrentamento de problemas diversos. Contudo, embora tenham grandes similaridades por lançar o olhar nas ações humanas, a narrativa não necessariamente necessita ser de cunho autobiográfico, uma vez que esse trata somente das trajetórias de vida pessoais/profissionais dos sujeitos. Ambas valorizam a subjetividade para a compreensão do fenômeno composto pela ação humana e podem aspectos de interesse para uma investigação educacional.

\section{CONSIDERAÇÕES FINAIS}

O objetivo central deste texto foi evidenciar a contribuição da narrativa para a produção de dados nas pesquisas em educação. Essa perspectiva metodológica tem sido empregada por diferentes pesquisadores no campo da educação e ensino, conforme evidenciamos. Pesquisas envolvendo currículo, formação docente e trajetórias de escolarização tem recorrido a essa perspectiva metodológica.

Consideramos que as entrevistas narrativas apresentam grande potencial para as pesquisas nas áreas de educação e ensino. Contudo, ainda necessitamos de estudos que aprofundem a contribuição teórico-metodológica dos estudos biográficos. É preciso discutir quais os critérios para a análise das narrativas: trazê- 
DOI: $10.12957 / \mathrm{e}-\mathrm{mosaicos} .2019 .41983$

las na íntegra no texto ou apenas excertos? Trabalhar com análise de conteúdo ou análise do discurso? A análise categorial tem sido a opção da maior parte dos estudos, mas a mônada na perspectiva benjaminiana é outra possiblidade, empregada principalmente nos estudos realizados pelo Grupo de Estudos de Práticas Curriculares e Narrativas Docentes, da Faculdade de Educação da UNICAMP.

Acreditamos que as entrevistas narrativas são autoformativas e heteroformativas. O texto autobiográfico é sempre inacabado e incompleto, passível de múltiplas interpretações. Assim, uma possibilidade para o emprego das entrevistas narrativas é que após a transcrição e textualização, elas sejam devolvidas e discutidas com os entrevistados, porque permite a produção de novos/outros sentidos para as experiências vividas/narradas.

\section{REFERÊNCIAS}

BERTAUX, D. Narrativas de vida: a pesquisa e seus métodos. Tradução de: CAVALCANTE,Z. A. C.; LAVALLÉE, D. M. G. São Paulo/Natal: Paulus/Ed. UFRN, 2010 BOLÍVAR, A.; DOMINGO, J.; FERNÁNDEZ, M. La investigación biográfico-narrativa en educación: enfoque y metodología. Madrid: La Muralla, 2001.

BOLÍVAR, A. ¿De nobis ipsis silemus? Epistemología de la investigación biográficonarrativa. Revista Electrónica de Investigación Educativa (REDIE), v. 4, n. 1, p. 1-26, 2002.

CLANDININ, D. Jean; CONNELLY, F. Michael. Pesquisa narrativa: experiência e história em pesquisa qualitativa. Uberlândia: EDUFU, 2011.

CUNHA, R. C. A pesquisa narrativa: uma estratégia investigativa sobre o ser professor. Anais $5^{\circ}$ Encontro de Pesquisa em Educação da UFPI, Teresina: Edufpi, v. $1,2009$.

FREITAS, F. de; GALVÃO, C. O uso de narrativas autobiográficas no desenvolvimento profissional de professores. Revista Ciências e Cognição, v. 12, p.219-233, 2007.

JOVCHELOVITCH, S.; BAUER, M. W. Entrevista narrativa. In: BAUER, Martin W.; GASKELL, George. Pesquisa qualitativa com texto, imagem e som: Um manual prático. Tradução de Pedrinho A. Guareschi. Petrópolis: Vozes. 2012.

MOURA, J.F. NACARATO, A. M. A entrevista narrativa: dispositivo de produção e análise de dados sobre trajetórias de professoras. Cadernos de Pesquisa, São Luís, vol. 24, n.01, p. 15-30, 2017. 
MUYLAERT, C. J. et al. Entrevistas narrativas: um importante recurso em pesquisa qualitativa. Rev ESC Enferm USP, 48, p.193-199, 2014.

SANTOS, H. T.; GARMS, G. M. Z. Método autobiográfico e metodologia de narrativas: contribuições, especificidades e possibilidades para pesquisa e formação pessoal/profissional de professores. CONGRESSO NACIONAL DE FORMAÇÃO DE PROFESSORES, 2.; CONGRESSO ESTADUAL PAULISTA SOBRE FORMAÇÃO DE EDUCADORES, 12., 2011, Águas de Lindóia. Anais. Congresso Nacional de Professores 12. Congresso Estadual sobre Formação de Educadores. São Paulo: UNESP; PROGRAD, 2014. p. 4094-4106 Disponível em:

<http://hdl.handle.net/11449/141766>.

SOUZA, E. C. Modos de narração e discursos da memória: biografização, experiências e formação. In: PASSEGGI, Maria da Conceição; SOUZA, Elizeu Clementino de. (Auto)Biografia: formação, territórios e saberes. Natal: EDUFRN; São Paulo: Paulus, 2008.

SOUZA, E. C. de. A arte de contar e trocar experiências: reflexões teóricometodológicas sobre história de vida em formação. Revista Educação em Questão, Natal, v. 25, n. 11, p. 22-39, jan./abr. 2006.

SOUZA, E. C. de. Diálogos cruzados sobre pesquisa (auto)biográfica: análise compreensiva-interpretativa e política de sentido. Revista Educação, Santa Maria, v. 39, n. 1, p. 39-50, jan./abr. 2014.

SOUZA, E. C. de. Memória educativa: narrativas de formação -recortes de um eu em crescimento e partilha. In: . O conhecimento de si: estágio e narrativas de formação de professores. Rio de Janeiro: DP\&A; Salvador, BA: UNEB, 2006.

SCHÜTZE, F. Pesquisa biográfica e entrevista narrativa. In: WELLER, W.; PFAFF, N. (Org.). Metodologias da pesquisa qualitativa em educação: teoria e prática. 2. ed. Petrópolis: Vozes, 2011.

WELLER, W. Tradições hermenêuticas e interacionistas na pesquisa qualitativa: a análise de narrativas segundo Fritz Schütze. Anais Reunião Anual da ANPEd, Caxambu, 2009.

WELLER, W.; OTTE, J. Análise de narrativas segundo o método documentário. Civitas, Porto Alegre, v. 14, n. 2, p. 325-340, maio-ago. 2014. 
DOI: $10.12957 / \mathrm{e}-\mathrm{mosaicos} .2019 .41983$

WELLER, W.; ZARDO, S. P. Entrevista narrativa com especialistas: aportes metodológicos e exemplificação. Revista da FAEEBA - Educação e

Contemporaneidade, Salvador, v. 22, n. 40, p. 131-143, jul./dez. 2013.

Recebido em 15 de abril de 2019.

Aceito em 19 de agosto de 2019.

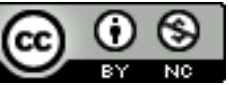

A e-Mosaicos Revista Multidisciplinar de Ensino, Pesquisa, Extensão e Cultura do Instituto de Aplicação Fernando Rodrigues da Silveira (CAp-UERJ) está licenciada com uma Licença Creative Commons - Atribuição-NãoComercial 4.0 Internacional.

Os direitos autorais de todos os trabalhos publicados na revista pertencem ao(s) seu(s) autor(es) e coautor(es), com o direito de primeira publicação cedido à e-Mosaicos.

Os artigos publicados são de acesso público, de uso gratuito, com atribuição de autoria obrigatória, para aplicações de finalidade educacional e não-comercial, de acordo com o modelo de licenciamento Creative Commons adotado pela revista. 